\title{
GREEN HOUSE GAS MITIGATION AND HEADLINE TARGETS OF EUROPE 2020 STRATEGY
}

\author{
János Lazányi \\ University of Debrecen, Faculty of Applied Economics and Rural Development
}

\begin{abstract}
Climate change is considered as one of the biggest challenges of XXI century and global action is needed to mitigate greenhouse gases (GHG) and adapt to changing water levels and temperatures, which affect food supply and ecosystem integrity. Climate change will have significant economic and social impacts in many regions of EU and sectors like agriculture is considered to bear greater adverse affects. Less developed regions and certain sections of society (the elderly and/or low-income households) are expected to suffer more from climate change. Climate change policy of EU, adopted in December 2008, includes ambitious targets for 2020. The policy is focused on a sustainable future with an energy-efficient economy by (i) cutting greenhouse gases by $20 \%$ (30\% if international agreement is reached), (ii) reducing energy consumption by $20 \%$ through increased energy efficiency and (iii) meeting $20 \%$ of energy needs from renewable sources. In the frame of the headline targets of Europe 2020 Strategy, this paper discusses most important greenhouse gas-emitting activities in agriculture, emphasizes the importance structural changes through the modernisation of infrastructure particularly in developing regions of EU and calls for enhancing the competitiveness of economy to promote energy efficiency.
\end{abstract}

Key words: Green house gas (GHG), Mitigation, Headline targets, Europe 2020 strategy

\section{Introduction}

Climate change is supposed to increase continental and sea temperatures, alters precipitation quantity and patterns, resulting in the increase of global average sea level and an expected increase in the severity of weather-related natural disasters. Addressing climate change requires two types of response. Countries must reduce GHG by taking mitigation action and take adaptation action to deal with the unavoidable impacts. Similar to mitigation activities, the integration of environmental concerns into the Common Agricultural Policy (CAP) is based on a distinction between ensuring a sustainable way of farming by avoiding harmful activities and providing incentives for public goods and services. The common rules and standards are mandatory for farmers to ensure that agricultural activity is undertaken in a sustainable way and preserve environment and the landscape. These rules and standards form the reference level to which the costs for complying with these obligations have to be born by the farmer, according to the "Polluter-PaysPrinciple". The Common Agricultural Policy ensures that farming and preservation of the environment go hand-inhand and plays a vital role in confronting new challenges such as biodiversity, water management and climate change.

On the other side, the Common Agricultural Policy has identified three priority areas for action to protect and enhance rural heritage: (i) the preservation and development of natural farming and traditional agricultural landscapes; (ii) water management and sustainable use and (iii) dealing with climate change. Measures of Rural Development Plan in EU countries promote the development of agricultural practices for preserving the environment and safeguarding the countryside. This is achieved by targeting rural development and promoting environmental friendly, sustainable practices, like agri-environment schemes. Farmers are encouraged to continue playing a positive role in the maintenance of the countryside and the environment.

As farming activities depend on climatic conditions, agriculture is directly exposed to climate change, but agriculture can also help to provide solutions to the mitigation of greenhouse gases. The EU recently conducted a study of the impact of climate change on different European agri-climatic zones and options for adaptation. Even if some climate changes may be positive for some North European regions, most will be negative, affecting regions already suffering from changing economic situation and environmental regulations. Farming will be most affected in the Southern and South-Eastern Regions of Europe, but according to the Intergovernmental Panel on Climate Change, the worst consequences may not be felt until 2050, even if significant adverse impacts are expected from more frequent extreme conditions in the short term.

In April 2009, the European Commission presented a White Paper laying out a European framework for action to improve Europe's resilience to climate change, emphasising the need to integrate adaptation into all key European policies and enhance co-operation at all levels of governance. Complementing to the White Paper, the report "Adapting to Climate Change: The Challenge for European Agriculture and Rural Areas" summarises the main impacts of climate change on EU agriculture, examines adaptation needs, describes the implications for the CAP and explores possible orientations for future action. It aims at engaging Member States and the farming community into actions on adaptation. 
The Adaptation Framework respects the principle of sustainable development and is focused on four pillars; (1) building a solid knowledge base on the impact and consequences of climate change, (2) integrating adaptation into key policy areas; (3) employing a combination of policy instruments (market-based instruments, guidelines, public-private partnerships) and (4) stepping up international cooperation on adaptation. The Adaptation Framework complements action of Member States and supports wider international efforts to adapt to climate change. In the United Nations Framework Convention on Climate Change, EU is working with partner countries towards a climate agreement and the Communication entitled "Towards a comprehensive climate change agreement in Copenhagen" addresses both adaptation and mitigation activities.

\section{Agriculture}

Agricultural activities contribute directly to emissions of greenhouse gases through a variety of different processes. Enteric fermentation, manure management and greenhouse gas emissions from agricultural soils are discussed in details. Emissions per capita reported in the agriculture were 0.948 tonnes of $\mathrm{CO}_{2}$-equivalent of greenhouse gases in 2007 at EU27 level. This represents $9.2 \%$ of total emissions, decreased from $11 \%$ in 1990 . GHG emission of fuel combustion is 7,680 $\mathrm{t} \mathrm{CO}_{2}$ eq. per capita out of which $1.933 \mathrm{t} \mathrm{CO}_{2}$ eq. per capita belonds to the transport sector. The GHG emission of international aviation 0.279 t $\mathrm{CO}_{2}$ eq. per capita and international maritime transport $0.343 \mathrm{t} \mathrm{CO}_{2}$ eq. per capita is calculated separately. Agricultural emissions account for almost $14 \%$ at global level. Agriculture is the most important source of two powerful gases, nitrous oxide $\left(\mathrm{N}_{2} \mathrm{O}\right)$ and methane $\left(\mathrm{CH}_{4}\right)$, which account for around $8.15 \%$ and $7.34 \%$ of total European emissions respectively. Between 1990 and 2007 carbon dioxid $\left(\mathrm{CO}_{2}\right)$ emission was reduced by $4.84 \%$, nitrous oxide emission by 27.14 and methane emission by $31.15 \%$, while emission of fluorinated gases increased by $31.06 \%$. Farming influences climate change mainly by producing two powerful greenhouse gases (i) methane from livestock digestion processes and stored animal manure, nitrous oxide from organic and mineral nitrogen fertilisers. Human-induced emissions in agriculture have a high degree of uncertainty as farming activities are very diverse and involve a wide range of biological processes, which naturally emit GHG. Behind the overall picture, there are considerable variations in the national situations (Figure 1). Large reductions occurred in Latvia, Bulgaria, Slovakia, Lithuania, Czech Republic, Estonia, Romania and Hungary, while Spaine increased GHG emission of agriculture between 1990 and 2007. Per capita GHG emission of agriculture was highest in Ireland and produced four times more than the mean value of EU-27 countries in 2007. Reduction in GHG emission was very fast between 1990 and 1994, mostly as results of transition in East Europen countries. The contribution of EU-15 member states countries to the GHG emission of EU increased until 2000 (Figure 2).

Agricultural activities also release carbon dioxide from fossil fuel use in buildings, equipment and machinery for field

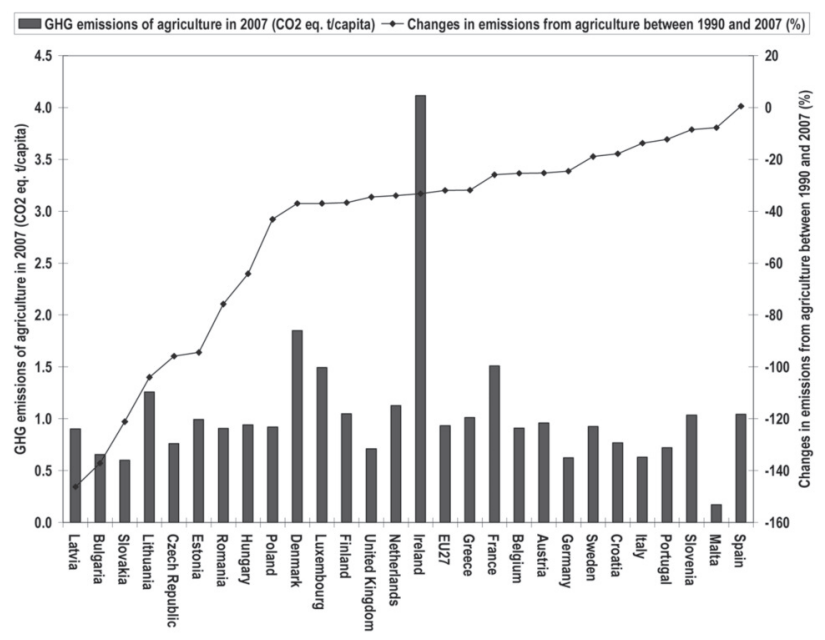

Figure 1: GHG emissions of agriculture in $2007\left(\mathrm{CO}_{2}\right.$ eq. t/capita) and changes in emissions between 1990 and 2007 (\%) (Data are from dataservice.eea.europa.eu)

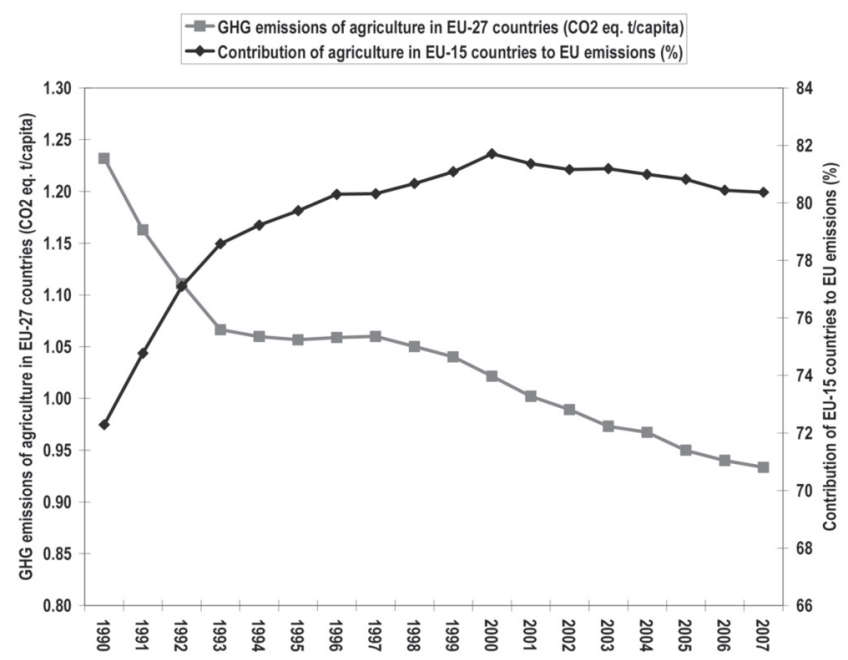

Figure 2: GHG emissions of agriculture in EU-27 countries $\left(\mathrm{CO}_{2}\right.$ eq. $\mathrm{t} /$ capita) and contribution of EU-15 countries to EU emissions (\%) (dataservice.eea.europa.eu)

operations, which account for around $1 \%$ of $\mathrm{CO}_{2}$ emissions of all sectors. Following the IPCC Guidelines for National Greenhouse Gas Inventories reporting scheme these emissions are not accounted in the 'agriculture' category but are included in the 'energy' inventory (IPCC, 1995). Further agriculture-related emissions, such as those from the manufacturing of fertilisers and animal feed, are included in the inventory on industrial processes.

\section{Methan emissions from enteric fermentation in domestic livestock}

Methane is produced in herbivores as a by-product of enteric fermentation, a digestive process by which carbohydrates are broken down by micro-organisms into simple molecules for absorption into the bloodstream. The amount of released methan depends on the type, age, and 
weight of the animal, the quality and quantity of the feed, and the energy expenditure of the animal. The type of digestive system also has a significant influence on the rate of methane emission. Ruminant animals have the highest emission of methan as results of methane-producing fermentation within the rumen. The main ruminant animals in EU are cattle, sheep and goats. Pseudo-ruminant animals, like horses and monogastric animals, like swine have relatively lower methane emissions because much less methane-producing fermentation takes place in their digestive systems (IPCC, 1995; 1996abc).

Methane $\left(\mathrm{CH}_{4}\right)$ is produced by the fermentation of feed and generally, the higher the feed intake, the higher is the methane emission. Feed intake is positively related to animal size, growth rate, and production (e.g., milk production, wool growth, or pregnancy). The amount of methane emitted by a population of animals is calculated by multiplying the emission rate per animal by the number of animals. To reflect the variation in emission rates among animal types, the population of animals is divided into subgroups, and an emission rate per animal is estimated for each subgroup. Types of population subgroup are recommended by the IPCC Guidelines for National Greenhouse Gas Inventories.

In some countries of EU, the dairy cattle population is comprised of two well-defined segments: high-producing improved varieties in commercial operations; and lowproducing cows managed with traditional methods. These two segments are evaluated separately by defining two dairy cattle categories. However, the dairy cattle category does not include cows kept principally to produce calves. Low productivity multi-purpose cows should be considered as non-dairy cattle. Emmision data of average milk production of dairy cattle are expressed in terms of kilograms of whole fresh milk produced per year per dairy cow, and can be obtained from countryspecific reports. Two or more dairy cattle categories are defined, the average milk production per cow is required for each category. Reduction of methane from enteric fermentation, still require substantial research efforts and practical experience before they could become general practice. Some of the most relevant measures, such as those linked to the nitrogen cycle are closely related to measures aiming at controlling nitrates and ammonia emissions and thus produce a range of substantive environmental benefits.

In the period of 1990-2007, methane emissions from enteric fermentation decreased by $31.1 \%$ in EU-27 countries, which represent 0.293 tons $\mathrm{CO}_{2}$ eq. per capita. Considering the GHG emissions of enteric fermentation in 2007, Ireland produced 2.050 tons of $\mathrm{CO}_{2}$ eq. per capita (Figure 3). This is nearly six times more than the averge of EU-27 coumtries. Large reductions occurred in Latvia, Bulgaria, Lithuania, Slovakia, Estonia, Czech Republic and Hungary, while Spaine and Portugal increased GHG emission from enteric fermentation (Figure 3). As results of transition in East Europen countries, reduction in GHG emission was very fast between 1990 and 1993. The contribution of EU-15 member states countries to the GHG emission of EU increased until 2001 (Figure 4).

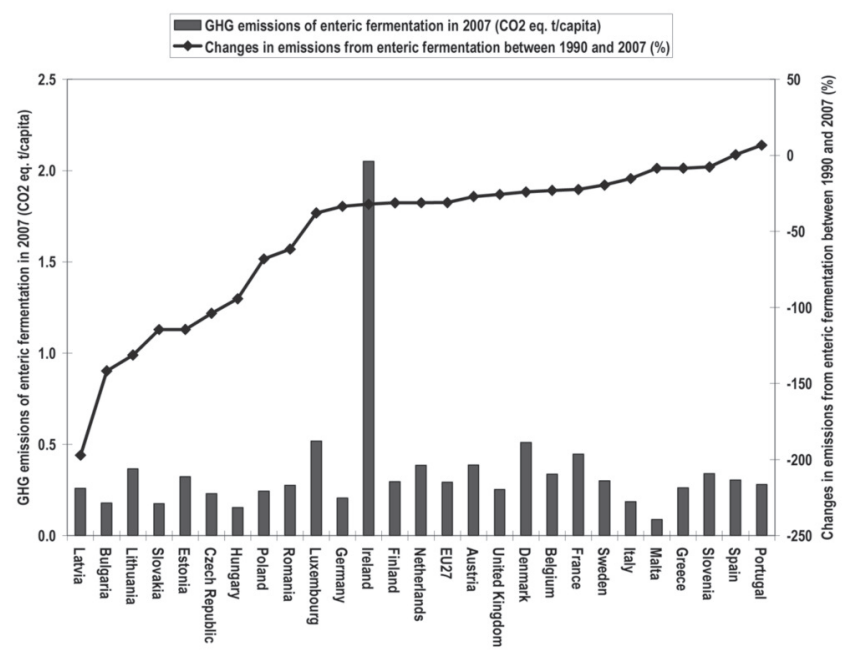

Figure 3: GHG emissions of enteric fermentation in $2007\left(\mathrm{CO}_{2}\right.$ eq. t/capita) and changes in emissions between 1990 and 2007 (\%) (Data are from dataservice.eea.europa.eu)

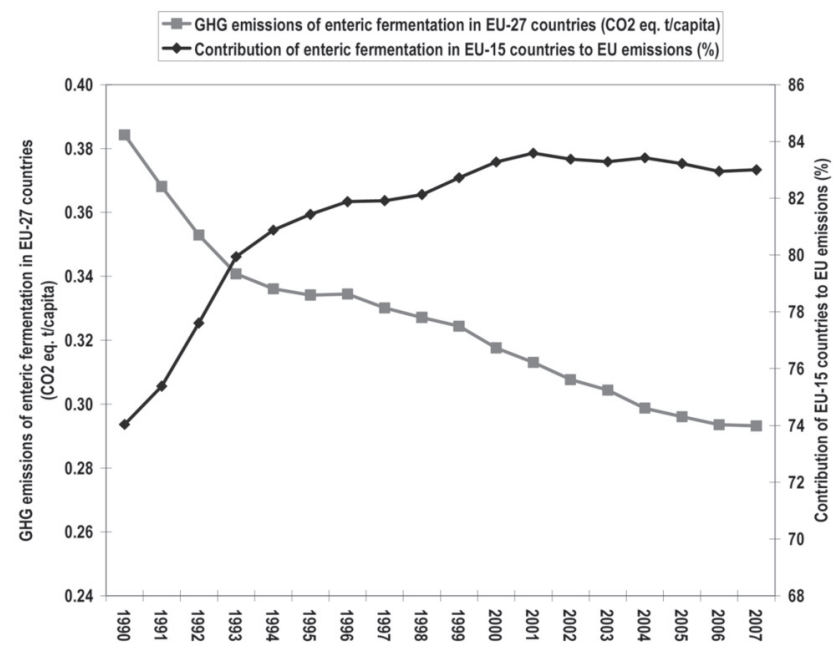

Figure 4: GHG emissions of enteric fermentation in EU-27 countries $\left(\mathrm{CO}_{2}\right.$ eq. t/capita) and contribution of EU-15 countries to EU emissions (\%) (dataservice.eea.europa.eu)

\section{Methane and nitrous oxide emissions from manure management}

This section presents a brief overview of the key factors affecting methane and nitrous oxide $\left(\mathrm{N}_{2} \mathrm{O}\right)$ emissions from these sources. Methane emissions from manure management are usually smaller than enteric fermentation emissions, and are principally associated with confined animal management facilities, where liquid manure is handled (IPCC, 1995). Methane is produced from the decomposition of manure under anaerobic conditions. These conditions often occur when large numbers of animals are managed in a confined area (dairy farms, beef feedlots, swine and poultry farms), where manure is typically stored in large piles or disposed of in lagoons. During storage, some manure nitrogen is converted to nitrous oxide. Emissions of $\mathrm{N}_{2} \mathrm{O}$ before the manure is added to soils are included in this category, while 
manure-related $\mathrm{N}_{2} \mathrm{O}$ emissions from soils are considered as agricultural soil emissions. Improved manure and slurry storage, processing and application techniques are technically feasible measures for reducing methane and nitrous oxide emissions. In regions with high animal densities, volumes of slurry and manure are high and the installation of anaerobic digestion plants is particularly effective in reducing emissions. Anaerobic digestion is the natural process of biological degradation of organic material in the absence of air. Anaerobic digester is a man-made system that uses this process to treat different types of organic waste and produce biogas. The biogas can be converted into heat and/or electricity. The process reduces gaseous emissions from the input material, while at the same time delivering valuable renewable energy.

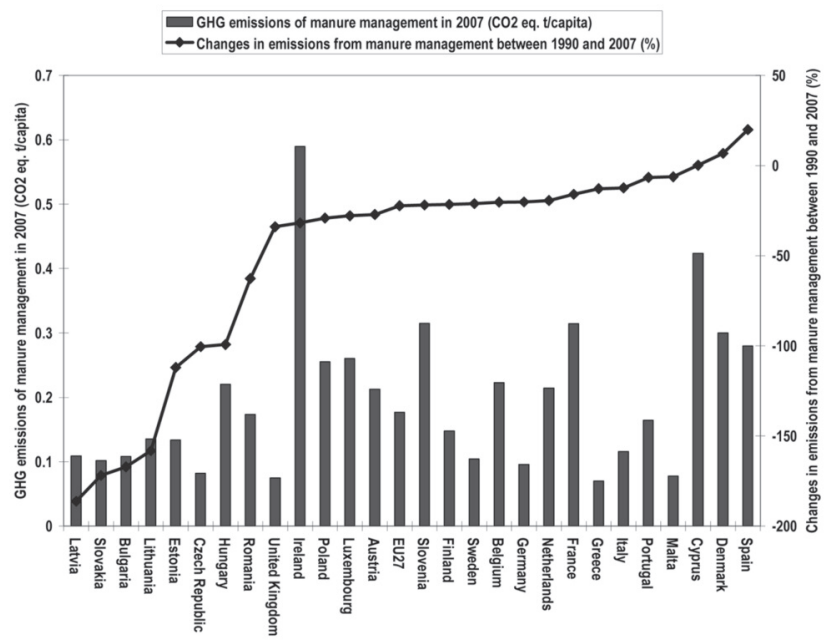

Figure 5: GHG emissions of manure management in $2007\left(\mathrm{CO}_{2}\right.$ eq. t/capita) and changes in emissions between 1990 and 2007 (\%) (Data are from dataservice.eea.europa.eu)

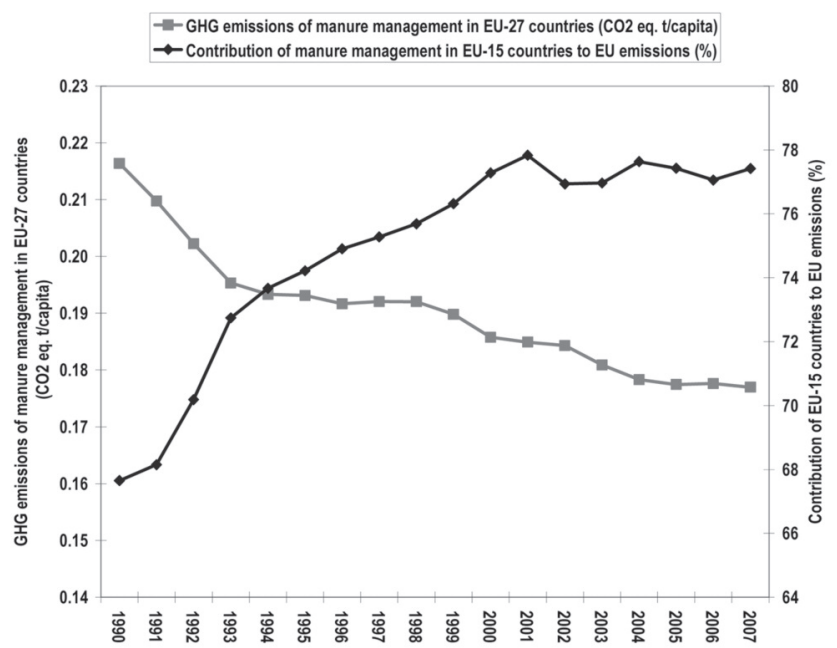

Figure 6: GHG emissions of manure management in EU-27 countries $\left(\mathrm{CO}_{2}\right.$ eq. t/capita) and contribution of EU-15 countries to EU emissions (\%) (dataservice.eea.europa.eu)

In the period of 1990-2007, methane and nitrous oxide emissions from manure management decreased by $22.3 \%$ in EU-27 countries, which represent 0.177 tons $\mathrm{CO}_{2}$ eq. per capita. Considering the GHG emissions of manure management, Ireland and produced 0.589 tons $\mathrm{CO}_{2}$ eq. per capita in 2007 (Figure 5). This is $233 \%$ more than the averge of EU-27 coumtries. Large reductions occurred in Latvia, Slovakia, Bulgaria, Lithuania, Estonia, Czech Republic and Hungary, while Cyprus, Denmark and Spaine increased GHG emission of manure management between 1990 and 2007 (Figure 5). Reduction in GHG emission was very fast between 1990 and 1993 mostly as results of transition in East Europen countries. The contribution of EU-15 member states countries to the GHG emission of EU increased until 2003 (Figure 6).

\section{Greenhouse gas emissions from agricultural soils}

Agricultural soils may also emit or remove nitrous oxide $\left(\mathrm{N}_{2} \mathrm{O}\right)$, carbon dioxide $\left(\mathrm{CO}_{2}\right)$, and/or methane $\left(\mathrm{CH}_{4}\right)$. The method for calculating national emissions of agriculture soils are decribed in IPCC Guidelines for National Greenhouse Gas Inventories (IPCC, 1996abc). In the methodology two sources of nitrous oxide are distinguished; (i) direct emissions from agricultural soils, and (ii) nitrous oxide emissions induced indirectly by agricultural activities. Anthropogenic input include synthetic fertiliser, nitrogen from animal wastes, nitrogen from increased biological $\mathrm{N}$ fixation, and nitrogen derived from cultivation of mineral and organic soils, through enhanced organic matter mineralisation. Nitrous oxide may be produced and emitted directly in agricultural fields, animal confinements or pastoral systems or be transported from agricultural systems into ground and surface waters through surface runoff, nitrogen leaching. In some cases, human sewage systems also transport the nitrogen into surface water. Ammonia and $\mathrm{NO}_{\mathrm{x}}$ emitted from soil may be transported and fertilise other systems, which leads to enhanced production of $\mathrm{N}_{2} \mathrm{O}$. Carbon dioxide emissions from soils are described in the section of Land-Use Land-Use Change and Forestry (LULUCF).

The methodology to calculate greenhouse gas emissions from agricultural soils are based on data available from FAO database and the methodology does not take into account different crops, soils and climates, which are known to regulate $\mathrm{N}_{2} \mathrm{O}$ production. Because of limited data availability to provide appropriate emission, these factors are generally not considered. Countries, which have data to show that default data are inappropriate for their country, should include a full explanation for the values used. The IPCC method also uses a linear extrapolation between $\mathrm{N}_{2} \mathrm{O}$ emissions and fertiliser nitrogen application. In most agricultural soils, mineral nitrogen enhances microbiological formation of $\mathrm{N}_{2} \mathrm{O}$, which in turn increases nitrification and denitrification rates. The amount of synthetic fertiliser nitrogen applied to soil is well documented in the FAO Annual Fertiliser Yearbook, but factors are needed to account for the loss of fertiliser in from of $\mathrm{NH}_{3}$ volatilisation and emission of nitric oxide. The IPCC methodology for 
assessing direct $\mathrm{N}_{2} \mathrm{O}$ emissions includes consideration of synthetic fertiliser, nitrogen from animal waste, enhanced $\mathrm{N}_{2} \mathrm{O}$ production due to biological $\mathrm{N}$-fixation, nitrogen from crop residue mineralisation and soil nitrogen mineralisation due to cultivation of Histosols (IPCC 2001ab). Significant amounts of $\mathrm{CO}_{2}$ can be removed from the atmosphere and stored in soils through a range of farming practices, such as organic farming; zero or reduced tillage systems that avoid or reduce soil disturbance; growing protein crops; planting hedgerows; maintenance of permanent pastures and conversion of arable land to grassland. Significant amounts of carbon can be removed with afforestation, as woody species hold much more carbon than most agricultural crops.

In the period of 1990-2007, methane and nitrous oxide emissions from agricultural soils decreased by $36.4 \%$ in EU27 countries, which represent 0.457 tons $\mathrm{CO}_{2}$ eq. per capita. There are considerable variations in emissions from agricultural soils between countries of EU (Figure 7). Large

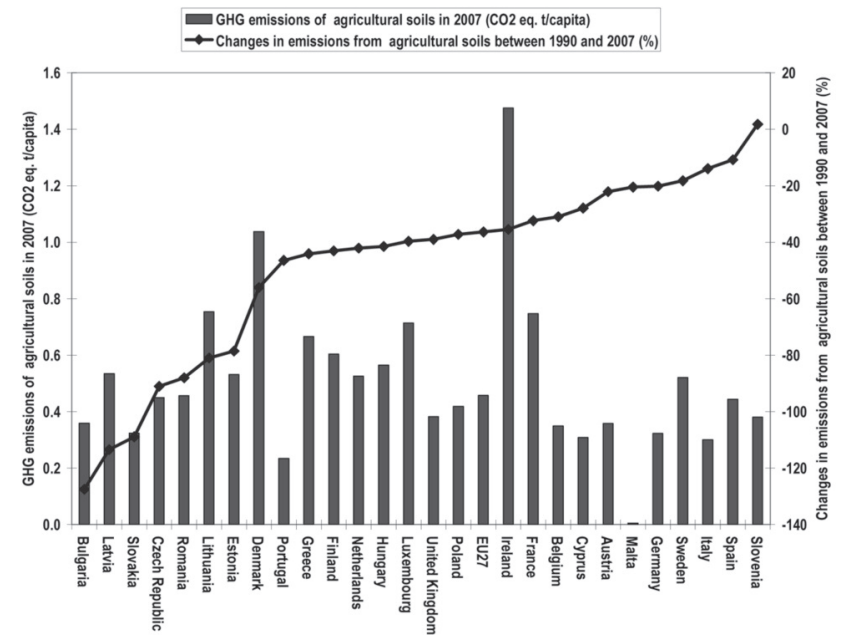

Figure 7: GHG emissions of agricultural soils in 2007 ( $\mathrm{CO}_{2}$ eq. t/capita) and changes in emissions between 1990 and 2007 (\%) (Data are from dataservice.eea.europa.eu)

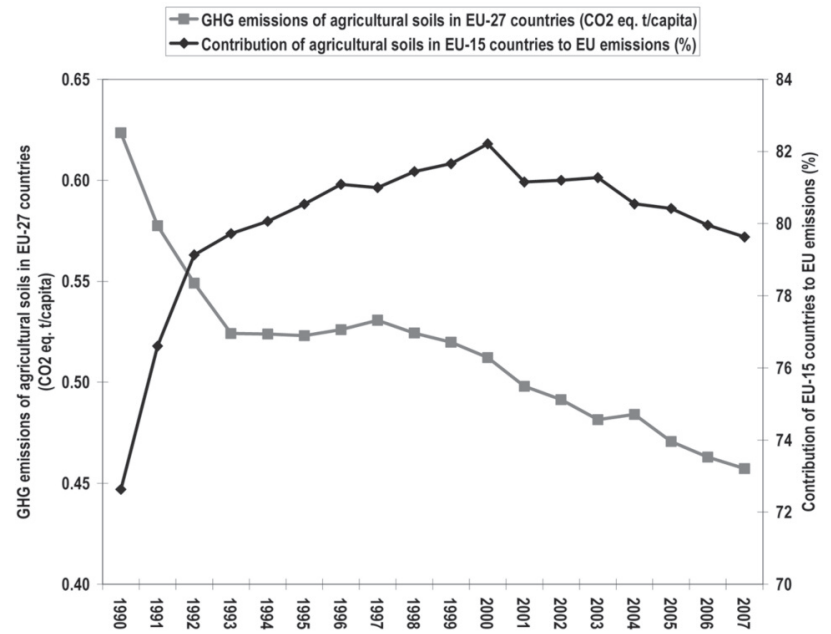

Figure 8: GHG emissions of agricultural soils in EU-27 countries $\left(\mathrm{CO}_{2}\right.$ eq. $\mathrm{t} /$ capita) and contribution of EU-15 countries to EU emissions (\%) (dataservice.eea.europa.eu) reductions occurred in Bulgaria, Latvia, Slovakia, Czech Republic, Romania, Lithuania and Estonia, while Slovenia increased GHG emission from agriculture soils between 1990 and 2007. In 2007, per capita GHG emission of agricultural soils ware highest in Ireland and Denmark. Reduction in GHG emission was very fast between 1990 and 1993, mostly as results of transition in East Europen countries. The contribution of EU-15 member states countries to the GHG emission of EU increased until 2001 (Figure 8).

\section{Land-use, land-use change and forestry}

Human activities, which change the way land is used, such as clearing of forests for agricultural use affect the amount of $\mathrm{CO}_{2}$ stored in biomass and soil (Rosenzweig and Parry, 1994; Schellnhuber et al. 2004). This mitigation potential is a focal point of calculating greenhouse gas emissions. The biosphere is a strong determinant of the chemical composition of the atmosphere and it has been true since the existence of the biosphere, when a large ammount of carbon, nitrogen, and sulphur gases was absorbed. There is strong evidence that the expanding human use of the biosphere for food, fuel and fibre is contributing to increasing atmospheric concentrations of greehouse gases ( Lal et al. 1997, Robert et al. 2000). Estimates of $\mathrm{CO}_{2}$ emissions due to land-use change vary considerably because of diversified human activity. According to IPCC Guidelines for National Greenhouse Gas Inventories, the fundamental basis for the methodology rest upon two linked themes (IPCC, 2001 ab). The flux of $\mathrm{CO}_{2}$ to or from the atmosphere is equal to changes in carbon stocks in the biomass and soils. The changes in carbon stocks can be estimated by establishing rates of change. Although there are data on which land-use change estimates, the rates of change in land use are difficult to establish (Gilliam and Hoyt, 1987; Reilly, 2002). A more practical approach is to make simple assumptions about the effects of land-use change on carbon stocks and the subsequent biological response to the land-use change, and to use these assumptions to calculate carbon stock changes and hence the $\mathrm{CO}_{2}$ flux (Friedlingstein et al. 2001). IPCC method also addresses the immediate release of $\mathrm{CH}_{4}, \mathrm{CO}, \mathrm{N}_{2} \mathrm{O}$ and $\mathrm{NO}_{\mathrm{x}}$ from the open burning of biomass after forest clearing. According to IPCC Guidelines for National Greenhouse Gas Inventories, the most important land-use changes that result in $\mathrm{CO}_{2}$ emissions and removals are:

- changes in forest and other woody biomass stocks: the most important effects of human interactions with existing forests includes commercial management, harvest of industrial roundwood and fuelwood, production and use of wood commodities;

- forest and grassland conversion: the conversion of forests and grasslands to pasture, cropland, or other managed uses can significantly change carbon stored in vegetation and soil;

- abandonment of croplands, pastures, plantation 
forests, or other managed lands, which regrow into their prior natural grassland or forest conditions.

- changes in soil carbon: In most cases, land that has been cultivated for many years is depleted in organic matter relative to its original state. In the temperate zone, considerable areas of formerly cultivated lands have been abandoned or converted to grassland and forest. If converted to perennial vegetation, either through land abandonment and natural succession or as an active management decision, such as conversion to pasture and conservation practices, soil carbon levels generally increase.

Intensive soil tillage is recognised as a significant factor causing soil organic matter declines in cultivated soils (Paustian et al. 1997, West and Post, 2002). Intensive tillage enhances decomposition of organic matter and supply crops with plant nutrients (Vetsch and Randall, 2000; Smith et al. 2001). Reduced tillage and particularly no-till practices have been shown to promote higher levels of organic matter in many regions, where productivity and organic matter inputs are not adversely related (Bouwman, 1990, Franzluebbers and Steiner, 2002). Reduced soil erosion and lower soil temperatures under surface mulches are particularly important attributes of no-till systems. Maintenance of soil carbon also depends on an adequate return of organic substrates, which serve as the raw material for organic matter formation (West and Post, 2002). In most agricultural systems, the primary sources of new carbon are crop residues. The amount of carbon returned in the form of residues depends on the total biomass yield and the proportion of that biomass, which is exported from the field. Of the carbon applied to soil in the form of crop residues, about one third typically remains after one year and about one-fifth remains after five years under temperate conditions. The remainder is returned to the atmosphere as $\mathrm{CO}_{2}$ via biological decomposition. The rate of decomposition, and the proportion of carbon retained by soil, is influenced by climate, soil conditions, placement (surface versus buried), and the composition of the residue. Some agricultural soils also receive significant inputs in the form of vegetation grown, at least in part, to provide additional carbon and other nutrients to the soil. For example, legumes are sometimes included in cropping systems as a 'green manure'. Similar benefits are derived from vegetative additions in 'alleycropping' systems. A third source of carbon is various byproducts, which are applied as soil amendments. The most noteworthy of these are animal manure, but some soils also derive appreciable carbon inputs from sewage sludge. Although such additions can significantly increase soil carbon, gains in the soil must be compared with alternative uses of the resources. For example, if sewage sludge decomposes more rapidly in soil than in fermeted form to produce biogas, the net effect will be an additional flux of carbon to the atmosphere. The estimate of $\mathrm{CO}_{2}$ fluxes is based on inventorying the areas and $\mathrm{C}$ stocks for land-use systems predominating within a particular climatic region. The most significant practices that differentiate land-use and management systems are clearing of native vegetation with conversion to cultivated crops or pasture; land abandonment; shifting cultivation; differing residue addition levels; ?differing tillage systems; and? agricultural use of organic soils.

In the period of 1990-2007, GHG removals of LULUCF increased by $13.6 \%$ in EU-27 countries, which represent 0.822 tons $\mathrm{CO}_{2}$ eq. per capita, although there are considerable variations between countries (Figure 9). Large removals from LULUCF occurred in Austria, Sweden, Lithuania, Slovenia, Finland, Estonia and Latvia, while between 1990 and 2007, Netherlands increased GHG emission from LULUCF. In 2007, Per capita GHG removal of LULUCF was highest in Latvia and removed more $\mathrm{CO}_{2}$ than the total GHG emission of the country. Mostly as result of transition in East Europen countries, reduction in GHG emission was very fast between 1990 and 1994. The contribution of EU-15 member states countries to the GHG emission of EU increased until 2000 (Figure 10).

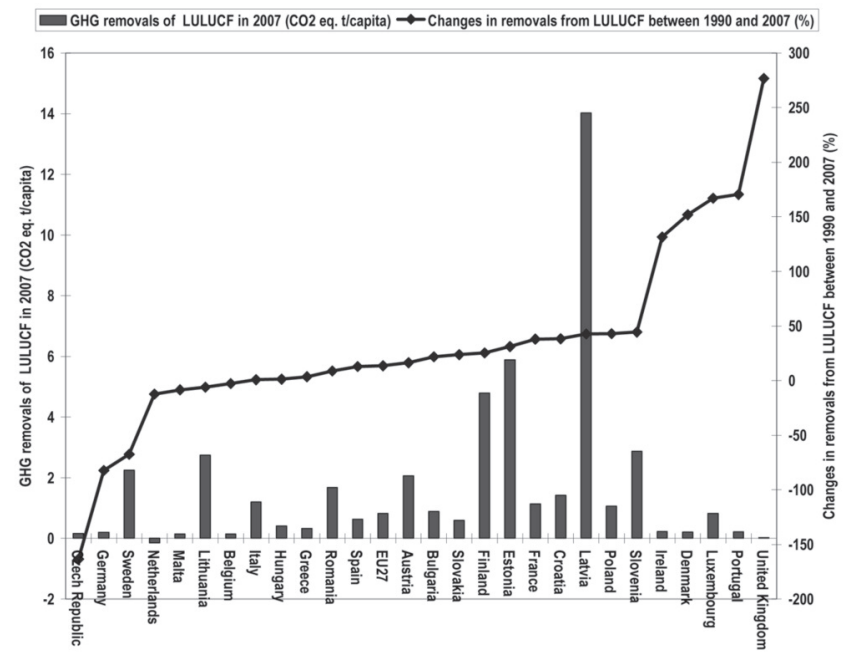

Figure 9: GHG removals of LULUCF in 2007 ( $\mathrm{CO}_{2}$ eq. t/capita) and changes in removals between 1990 and 2007 (\%)(Data are from dataservice.eea.europa.eu)

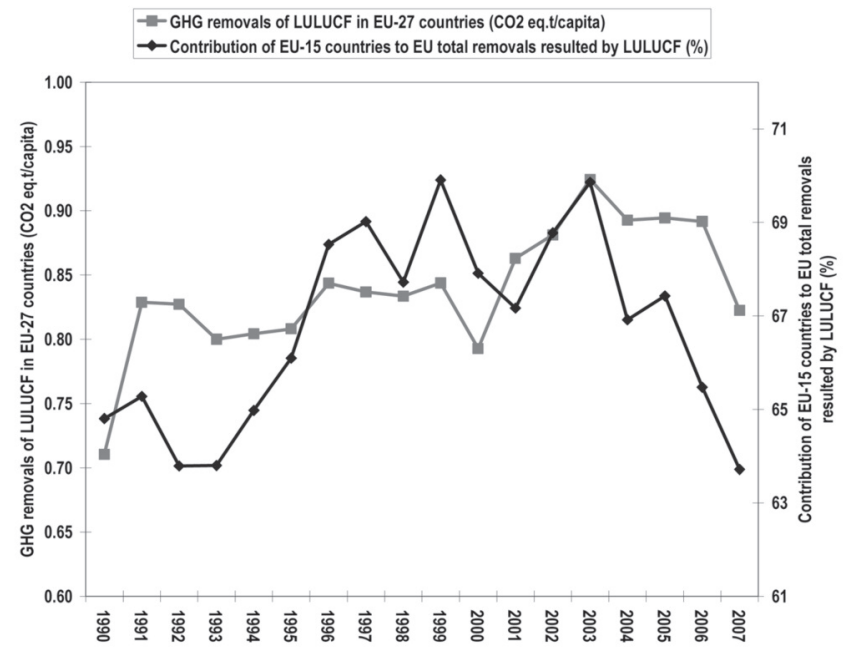

Figure 10: GHG removals of LULUCF in EU-27 countries $\left(\mathrm{CO}_{2}\right.$ eq. t/capita) and contribution of EU-15 countries to EU removals (\%) (dataservice.eea.europa.eu) 


\section{Mitigation potential of EU agriculture}

Agriculture has further possibilities to reduce the emissions of methane, nitrous oxide and carbon dioxide released by farming activities and by maintaining and sequestering carbon in farmland soils (Bruinsma, 2003). There are management options that have the potential to reduce methane and nitrous oxide emissions below current levels. These include the reduction in use of fertiliser and agricultural input, livestock and manure management (Parry et al. 2004). Precision farming, optimisation of mineral and organic nitrogen application and overall reduction of external inputs (e.g. in organic farming) also contributes to the reduction of GHG emissions. Production of mineral fertilisers and other chemical products is energy intensive. GHG emission of ammonia production in EU-27 countries was 0.056 tons $\mathrm{CO}_{2}$ eq. per capita in 2007. Extensive forms of pasture management in livestock rearing, technical additives to control methane from digestion processes and improvements in the nutrition patterns (diet and the level of food intake) of livestock influence the amount of methane releases from enteric fermentation and manure management. Less intensive forms of rearing is beneficial for landscape conservation and bio-diversity. Improved manure storage, such as appropriate installations for different types of animal manure and slurry, application of immediate incorporation into soils and better accounting of nitrogen content can contribute to the reduction of GHG emissions. Processing of animal waste in anaerobic digestion plants for the production of biogas has been identified as one of the most promising measures and is highly cost-effective in farms with high animal densities and large volumes of slurry and manure. These technical and management options vary in costeffectiveness. One of the best practices is improved storage of manure and the accounting of its nitrogen content when applied to the fields. The costs and benefits of agricultural mitigation options are diverse. Regional differences are influenced by a number of factors such as farm characteristics (size, location, yields, level of inputs), climatic and environmental conditions (land and soil characteristics, water availability), the degree to which mitigation measures compete with traditional agricultural practices and profitability (e.g., extensive grazing systems or fertilization), and the incentives in place such as financial support.

\section{Mitigation and Europe 2020 strategy}

There are large regional differences in mitigation potential and in the costs and benefits of mitigation options. It is necessary to tailor policy measures to specific conditions of farming. The Europe 2020 strategy puts innovation and green growth at the heart of its blueprint for competitiveness, and proposes tighter monitoring of national reform programmes to get out of the crisis and to prepare the foundation for the EU economy for the next decade. The Commission identifies three key drivers for growth to be implemented at national levels and regional: (i) smart growth (fostering knowledge, innovation and education), (ii) sustainable growth (making our production more resource efficient while boosting European competitiveness) and (iii) inclusive growth (raising participation in the labour market, the acquisition of skills and the fight against poverty). The battle for growth and jobs requires land stewardship at the uppermost political level and RTD activities across Europe. Progress should be measured against five representative headline targets: $75 \%$ of the population aged 20-64 should be employed; $3 \%$ of the EU's GDP should be invested in R\&D; the "20/20/20" climate/energy targets should be met. The share of early school leavers should be under $10 \%$ also in rural erea and at least $40 \%$ of the younger generation should have a degree to reduce the number of people living in poverty.

Total GHG emissions of 1-7 sectors (excluding LULUCF) were reduced from 11.645 tons of $\mathrm{CO}_{2}$ eq. per

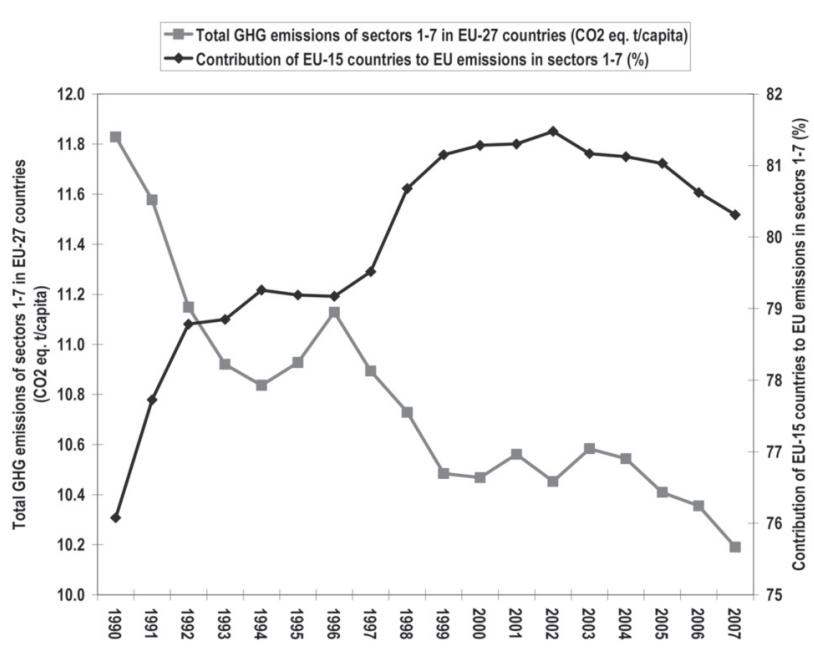

Figure 11: Total GHG emissions of sectors 1-7 (excluding LULUCF) in EU27 countries $\left(\mathrm{CO}_{2}\right.$ eq. t/capita) and contribution of EU-15 countries to EU emissions (\%) (Data are from dataservice.eea.europa.eu)

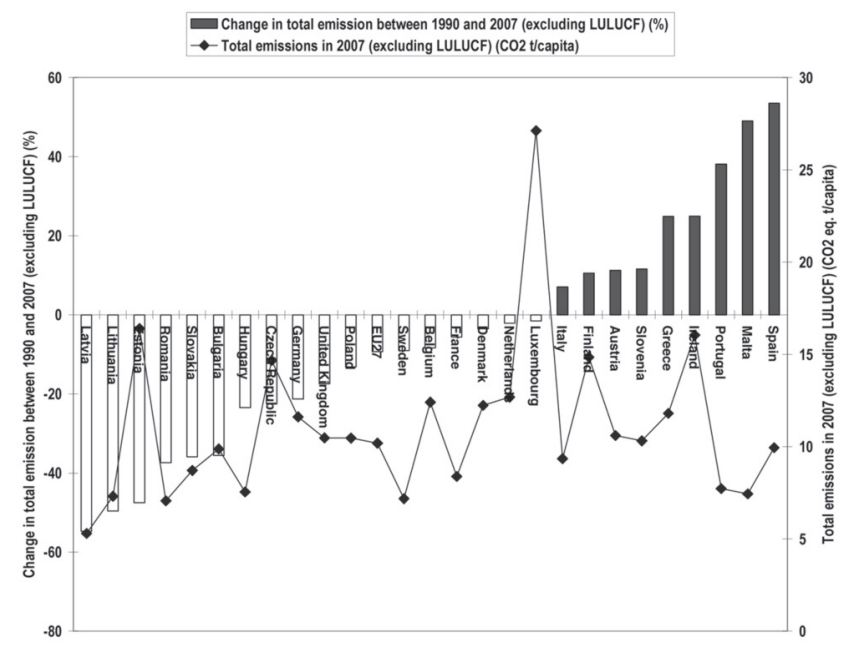

Figure 12: Total emissions in 2007 ( $\mathrm{CO}_{2}$ eq. $\mathrm{kg} /$ euro) (excluding LULUCF) and change in total emission between 1990 and 2007 (\%) (Data are from dataservice.eea.europa.eu) 
capita to 10.343 tons of $\mathrm{CO}_{2}$ eq. capita in EU-27 countries between 1990 and 2007. The reduction took place in East Europen countries and EU-15 countries have increased their contribution to the GHG emission from $76.1 \%$ to $80.3 \%$ (Figure 11). Changes in total emission between 1990 and 2007 do not show any correlation with the total GHG emission in year 2007 (Figure 12). GHG emission was reduced in Hungary, Slovakia, Lithuania, Czech Republic, Romania, Poland, Estonia and Bulgaria, where GHG efficiency is low (Figure 13 and 14).

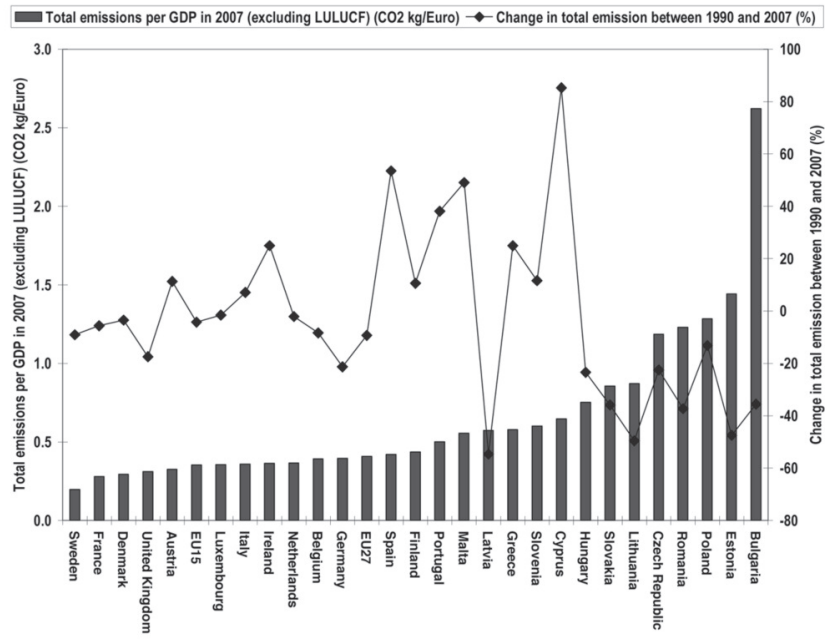

Figure 13: Total emissions per GDP in 2007 ( $\mathrm{CO}_{2} \mathrm{~kg} /$ Euro) (excluding LULUCF) and change in total emission between 1990 and 2007 (\%) (Data are from dataservice.eea.europa.eu)

Hungary, Slovakia, Lithuania, Czech Republic, Romania, Poland, Estonia and Bulgaria have paid a high price for the challenging data in GHG emission reduction as their agricultural production went back in a similar scale. Except for cereals, the EU is contributing less and less to world total food and agricultural production. According to FAO statistics, EU-27 countries produced $27 \%$ of total world meat production in 1961 and this has reduced to $15 \%$. Contribution of EU countries to total world fruit production was more than $30 \%$ at the beginning of the 1960s and now it is close to $10 \%$. EU produced more than $20 \%$ of vegetables and this number has reduced to less than $7 \%$. To ensure adequate food supplies, produce row material for industry and energy sector, preserve the countryside and provide a reasonable living for agricultural and related populations we need Europe 2020 strategy. Measures of Rural Development Progammes (RDP) may not achieve their optimal effect without the realization of comprehensive Europe 2020 strategy. The key drivers for growth are valid for rural area. Number one is smart growth for fostering knowledge, innovation and education in agriculture. The second is sustainable growth for making our production more resource efficient while boosting European competitiveness in food and agriculture sector. The third one is inclusive growth, which is especially valid for rural area, where the employment rate is low and the acquisition of skills to fight against poverty is difficult. Progress in rural development and in CAP should be measured against five representative headline targets: $75 \%$ of the population aged 20-64 should be employed; $3 \%$ of the GDP should be invested in R\&D even in rural area; the "20/20/20" climate/energy targets should be met by agriculture. The share of early school leavers should be under $10 \%$ also in rural erea, reduce the number of people living in poverty and improve skills and knowledge of the younger generation - not only in volume, but also in quality - to reduce assimetrical interdependence in and of rural region.

\section{References}

Bouwman, A.F., 1990. Exchange of greenhouse gases between terrestrial ecosystems and the atmosphere. In: Bouwman, A.F. (Ed.), Soils and the Greenhouse Effect. Wiley, New York, USA, pp. 61-127.

Bruinsma, J. 2003 World agriculture: towards 2015/2030. London: Earthscan Publications Ltd.

Commission of the European Communities (2009): Adapting to climate change: Towards a European framework for action. White Paper, COM(2009) 147.

Commission of the European Communities (2009): Adapting to climate change in Europe options for EU action. Green Paper, $\operatorname{COM}(2007) 354$.

Commission of the European Communities (2009): The role of European agriculture in climate change mitigation. Commission staff working document, SEC (2009) 1093.

Decision No 406/2009/EC of the European Parliament and of the Council of 23 April 2009 on the effort of Member States to reduce their greenhouse gas emissions to meet the Community's greenhouse gas emission reduction commitments up to 2020 .

European Commission (2000): White paper on food safety. Brussels, COM (1999) 719.

European Commission (2007): The Common Agricultural Policy explained. European Commission, Directorate-General for Agriculture and Rural Development.

European Commission, DG Agriculture and Rural Development (2009): Agricultural policy perspectives. Member States factsheets - European Union.

European Commission, DG Agriculture and Rural Development (2010): Agricultural policy perspectives. The CAP in perspective: from market intervention to policy innovation.

Franzluebbers AJ, Steiner JL (2002): Climatic influences on soil organic carbon storage with no tillage. In: (Kimble JM, Lal R, Follett RF eds): Agricultural Practices and Policies for Carbon Sequestration in Soil, Lewis, Boca Raton. 71-85 p.

Friedlingstein, C.B., Goodale, P., Heimann, C., Houghton, M., Melillo, R.A., Moore, J.M., Murdiyarso, B., Noble, D., Pacala, I., Prentice, S.W., Raupach, I.C., Rayner, M.R., Scholes, P.J., Steffen, R.J., Wirth, W.L. (2001): Recent patterns and mechanisms of carbon exchange by terrestrial ecosystems. Nature 414, 169-172 p.

Gilliam, J.W., Hoyt, G.D. (1987): Effect of conservation tillage on fate and transport of nitrogen. In: (Logan, T.J., Davidson, J.M., Baker, J.L., Overcash, M.R. Eds.), Effects of Conservation Tillage on Groundwater Quality. Lewis Publishers, Chelsea, Michigan. 217-240 p. 
IPCC (1995): Climate Change: Impacts, Adaptations and Mitigation of Climate Change. Scientific-Technical Analyses, Cambridge Univ. Press, Cambridge.

IPCC (1996): Guidelines for National Greenhouse Gas Inventories. ?The Greenhouse Gas Inventory Reporting Instructions.

IPCC (1996): Guidelines for National Greenhouse Gas Inventories. The Greenhouse Gas Inventory Workbook.

IPCC (1996): Guidelines for National Greenhouse Gas Inventories. The Greenhouse Gas Inventory Reference Manual.

IPCC (2001a): Climate change 2001: The scientific basis. In: (Houghton et al.) Contribution of working group I to the third assessment report of the Intergovernmental panel on climate change. Intergovernmental Panel on Climate Change Cambridge University Press, Cambridge 1-881 p.

IPCC (2001b) Climate change: Impacts, adaptation, and vulnerability. Contribution of working group II to the third assessment report of the intergovernmental panel on climate change. Cambridge, UK: Cambridge University Press.

Lal, R., J.M. Kimble, R. F. Follett and C. V. Cole (1997): The Potential of U.S. Cropland to Sequester Carbon and Mitigate the Greenhouse Effect. Sleeping Bear Press Inc. Chelsea MI. 1-128 p.

Parry, M. L., Rosenzweig, C., Iglesias, A., Livermore, M. \& Fischer, G. (2004): Effects of climate change on global food production under SRES emissions and socio-economic scenarios. Global Environ. Change 14, 53-67 p.
Paustian K,Andren O, Janzen HH et al. (1997) Agricultural soils as a sink to mitigate CO2 emissions. Soil Use and Management, 13, 230-244 p.

Reilly, J. M. (2002): Agriculture: The Potential Consequences of Climate Variability and Change for the United States, Cambridge: Cambridge University Press. 1-136 p.

Robert T. Watson, Ian R. Noble, Bert Bolin, N. H. Ravindranath, David J. Verardo and David J. Dokken (eds.) (2000): Land Use, Land-use Change, and Forestry. Special Report of the Intergovernmental Panel on Climate Change, Geneva Switzerland. Cambridge University Press U.K. 1-375p.

Rosenzweig, C. \& Parry, M. L. (1994): Impacts of climate change on world food supply. Nature 367, 133-138 p.

Schellnhuber, H. J., Turner, B. L., Wasson, R. J. (eds.) (2004): Global change and the Earth system: a planet under pressure. Berlin, Heidelberg, New York: Springer-Verlag.

Smith P, Goulding KW, Smith KA (2001): Enhancing the carbon sink in European agricultural soils: including trace gas fluxes in estimates of carbon mitigation potential. Nutrient Cycling in Agroecosystems, 60, 237-252 p.

Vetsch JA, Randall GW (2000): Enhancing no-tillage systems for corn with starter fertilizers, row cleaners, and nitrogen placement methods. Agronomy Journal, 92, 309-315 p.

West TO, Post WM (2002): Soil organic carbon sequestration rates by tillage and crop rotation: a global data analysis. Soil Science Society of America Journal, 66, 1930-1946 p. 
